\title{
Photosynthetic responses of Halophila stipulacea to a light gradient. I. In situ energy partitioning of non-photochemical quenching
}

\author{
John W. Runcie ${ }^{1, *}$, Diogo Paulo ${ }^{2}$, Rui Santos ${ }^{2}$, Yoni Sharon ${ }^{3,4}$, Sven Beer ${ }^{4}$, João Silva ${ }^{2}$ \\ ${ }^{1}$ School of Biological Sciences, University of Sydney, New South Wales 2006, Australia \\ ${ }^{2}$ ALGAE-Marine Plant Ecology Research Group, Center of Marine Sciences (CCMAR), Universidade do Algarve, \\ Campus de Gambelas, 8005-139 Faro, Portugal \\ ${ }^{3}$ The Interuniversity Institute for Marine Sciences, POB 469, Eilat 88103, Israel \\ ${ }^{4}$ Department of Plant Sciences, Tel Aviv University, Tel Aviv 60078, Israel
}

\begin{abstract}
The quantum yield of photosystem II $\left(\phi_{\mathrm{II}}\right.$, also termed $\Delta F / F_{\mathrm{m}}{ }^{\prime}$ or $F_{\mathrm{v}} / F_{\mathrm{m}}$ in light- or darkacclimated plants, respectively) of the tropical seagrass Halophila stipulacea was measured in situ using modulated fluorescence techniques over diel periods at a range of depths. Photosynthetic electron transport rates (ETRs), as derived from $\phi_{\text {II }}$ values at specific ambient photosynthetically available radiation (PAR) irradiances, increased in direct proportion to increasing irradiance in the morning and, at shallow sites $(7$ to $10 \mathrm{~m})$, reached saturating rates and then declined in the afternoon with lower PAR-specific ETRs. On the other hand, plants at 32 to $33 \mathrm{~m}$ showed no saturation even at midday, and the percentage reduction in PAR-specific afternoon ETRs was less than that of the shallower plants. The use of an automated shutter in the measuring device enabled non-photochemical quenching due to down-regulation and basal intrinsic non-radiative decay to be distinguished. While midday values of down-regulation were lower in deeper water, basal intrinsic non-radioactive decay remained fairly constant at 30 to $40 \%$ at all depths, with more variation in shallow waters. The maximal $\phi_{\text {II }}$ (i.e. $F_{\mathrm{v}} / F_{\mathrm{m}}$ ) reached similar values at midnight regardless of depth. H. stipulacea acclimates to the widely varying irradiances across this depth gradient by regularly modulating down-regulationbased non-photochemical quenching processes, while dissipating a large proportion of light energy through intrinsic decay regardless of depth.
\end{abstract}

KEY WORDS: Depth gradient · Halophila stipulacea · Irradiance $\cdot$ Nonphotochemical quenching · PE curves $\cdot$ Photosynthesis $\cdot$ Pigments

\section{Resale or republication not permitted without written consent of the publisher}

\section{INTRODUCTION}

Seagrass meadows dominate many shallow estuaries and marine embayments, yet at a global scale seagrasses are in decline (Orth et al. 2006). While this decline has been largely attributed to human activity through increased light attenuation caused largely by higher sediment loads and algal densities, other factors such as eutrophication, heavy metals and petrochemical pollution have a significant impact on seagrass survival (Orth et al. 2006, Ralph et al. 2007). The capacity for a seagrass species to conduct photosynthesis such that the net carbon balance is positive is vital for the survival and resilience of a meadow. Thus considerable research effort over the last half-century has maintained a focus on seagrass growth and photosynthesis (e.g. Larkum 1976, Lee et al. 2007).

The seagrass Halophila stipulacea is an integral component of the the Gulf of Aqaba coral reef ecosystem in the Red Sea (Edwards \& Head 1987), where it can be found in extensive monospecific beds. H. stipulacea has a generally wide ecological range, growing from the intertidal to depths $>50$ to $70 \mathrm{~m}$ (Hulings 1979, Lipkin 1979, Beer \& Waisel 1982). This is in con- 
trast with the seagrass Halodule uninervis that coexists in shallow waters in the northern Red Sea, Gulf of Aqaba, but does not extend as deeply (Beer \& Waisel 1982). Mechanisms that enable the survival of H. stipulacea in shallow and deep waters may include an insensitivity to pressure due to its lack of substantial gas lacunae (Beer \& Waisel 1982) and its capacity for chloroplast clumping (Schwarz \& Hellblom 2002, Sharon \& Beer 2008).

Since the advent of submersible modulated fluorometers in the 1990s, chlorophyll fluorescence techniques have been widely used in the examination of in situ seagrass photophysiology (e.g. Beer et al. 1998, 2000), and the effects of varying irradiance with increasing turbidity or depth have been examined in some detail (Lee et al. 2007). However, most in situ fluorescence studies have been constrained by the necessity for divers to make the measurements, limiting studies to a combination of maximum depth, frequency and duration of measurements at these depths. Fewer studies have taken advantage of logging functions available in commercially available instruments (e.g. Winters et al. 2003, Schwarz et al. 2003); other studies have developed custom devices for continuous measurements over time of multiple replicate samples (Runcie \& Riddle 2004, 2006, Runcie \& Durako 2004).

The quantum yield $(\phi)$ of a light-dependent process is defined as the ratio of the rate of that process to the rate of photon absorption. In unstressed green plants and algae, the light-dependent process of photochemical energy conversion uses approximately $83 \%$ of light absorbed, thus the quantum yield of photosynthesis is 0.83. Modulated fluorescence techniques are particularly useful for measuring the quantum yield of photochemical energy conversion in photosystem II (PSII), $\phi_{\text {II }}$, and by difference, the quantum yield of nonphotochemical energy conversion in PSII, $\phi_{\mathrm{NPQ}}$.

Diel changes in $\phi_{\text {II }}$ describe how a phototroph responds to irradiance and can be used with other measurements to estimate net carbon gain (Beer et al. 2000, Longstaff et al. 2002). However, irradiance energy absorbed by PSII that cannot be directed to photochemistry is (by definition) directed to several classes of non-photochemical quenching (NPQ) processes. Of these, the generation of singlet oxygen can cause intensive damage to internal structures if the absorbed energy is not effectively dissipated through other NPQ processes (Müller et al. 2001).

Kornyeyev \& Holaday (2008) separated NPQ into 4 components: (1) fluorescence is generally a very small proportion of NPQ (a few percent at most) and is generally disregarded; (2) regulated, dark-reversible dissipation is generally activated in response to irradiance stress; (3) constitutive thermal dissipation can be regarded as the (assumed) invariant $\sim 27 \%$ of light directed to non-photochemical processes when absorbed by non-stressed phototrophs; and (4) induced thermal dissipation is associated with PSII photoinactivation and is sometimes termed photoinhibition. Kramer et al. (2004) pooled the 2 thermal dissipation components together and termed them basal intrinsic non-radiative decay. For simplicity we adopt this latter term to describe thermal dissipation.

As part of the recent Group for Aquatic Primary Productivity (GAP) workshop in Eilat (April 2008, see www.gap-aquatic.org/), we studied various photophysiological aspects of the seagrass Halophila stipulacea, in situ. In the present study, we determined how irradiance energy absorbed by PSII is allocated to photochemistry versus non-photochemical processes in plants exposed to very different irradiances along a wide depth gradient. By determining diel changes in electron transport rates at various depths (8 to $33 \mathrm{~m}$ ), we aimed to distinguish differential responses in terms of photochemical and non-photochemical use of the contrasting ambient photosynthetically available radiation (PAR) irradiances at each depth. The specific objectives of the present study were to determine how excitation energy is allocated within $H$. stipulacea to photochemistry, down-regulation and basal intrinsic non-radiative decay processes when exposed to different irradiances (at various depths), and how the allocation to these processes varies during the onset of irradiance stress and recovery. A parallel study was also conducted to examine acclimatory responses of H. stipulacea transplanted across the 3 depths (Sharon et al. 2009, this Theme Section).

\section{MATERIALS AND METHODS}

Study sites and seagrass species. Halophila stipulacea (Forsskål) Ascherson was examined in situ at 8, 18 and $33 \mathrm{~m}$ depth just south of the Inter-University Institute (IUI) in Eilat, the Gulf of Aqaba, northern Red Sea $\left(29^{\circ} 30^{\prime} \mathrm{N}, 34^{\circ} 55^{\prime} \mathrm{E}\right)$ during April 2008. Automated chlorophyll fluorescence measurements were set up at each depth using SCUBA. Individual leaves separated from each other by $\geq 10 \mathrm{~cm}$ were examined. Selected samples were taken to the laboratory for leaf absorbance determinations.

In situ irradiance and $\boldsymbol{K}_{\mathrm{d}}$ measurements. Irradiance was measured in situ during fluorometer deployments using cosine-corrected irradiance sensors incorporated in the custom fluorometers, and is termed incident irradiance or $I_{\mathrm{i}}$. Data was compared with measurements in

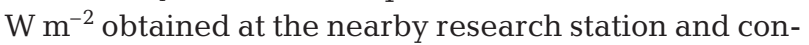
verted to $\mu \mathrm{mol}$ photons $\mathrm{m}^{-2} \mathrm{~s}^{-1}$ by multiplying by 4.6 (McCree 1981). Occasional in-air measurements and depth profiles using a LiCor 190SA quantum sensor 
were also taken from a boat in the vicinity of the study site; those in-air irradiance values were similar to values measured at the research station. All light sensors were calibrated against the LiCor 190SA quantum sensor. The light attenuation coefficient $K_{\mathrm{d}}$ was calculated from depth profile data.

Absorbance measurements. The absorption factor (AF) of 12 different leaves was assessed and averaged at each depth $(8,18$ and $33 \mathrm{~m})$ throughout the day $(06: 00,10: 00,12: 30,16: 00$ and $18: 00 \mathrm{~h})$ by determining the reduction of ambient irradiance (or artificial irradiance at dawn and dusk) caused by a single leaf placed over the light sensor of a Diving-PAM fluorometer (Walz, Effeltrich). This reduction in irradiance was converted to a proportion. For example, a $50 \%$ reduction in irradiance caused by placing a leaf over the light sensor corresponded to an AF value for that leaf of 0.5 (Sharon $\&$ Beer 2008). It was assumed that absorbance by photosynthetic pigments contributed $96 \%$ of the overall absorbance in Halophila stipulacea (as found earlier, Sharon \& Beer 2008); the absorbance of other compounds was therefore ignored. The measured AF values were regressed against time separately for morning and afternoon measurements and thus 2 linear relationships were determined for each depth. The trajectory of these regression lines indicated the direction and rate of change in absorbance throughout the day (a proxy for chloroplast clumping, Sharon \& Beer 2008), and enabled the estimation of AF by interpolation at each depth for each fluorescence measurement.

Twelve absorbance values were obtained at each depth at (approximately) each time; differences between mean AF values at each depth at dawn and dusk were compared using ANOVA after testing for homogeneity of variances.

In situ modulated fluorescence measurements. Two designs of custom submersible fluorometer (Aquation, Australia) were used that excite chlorophyll a fluorescence with a modulated blue light (470 nm lightemitting diode, LED) before and during a $0.8 \mathrm{~s}$ blueenriched white saturating pulse provided by a $10 \mathrm{~W}$ LED (Luxeon, Lumileds Lighting). A far-red LED $(735 \mathrm{~nm})$ incorporated into the fluorometers was activated for $5 \mathrm{~s}$ prior to saturating pulse measurements to facilitate the opening of PSII centres and hence determine $F_{\mathrm{o}}{ }^{\prime}$ (i.e. minimal fluorescence intensity with all PS II reaction centers open in a light-acclimated state). The sensor head of one fluorometer design closed over the sample when taking a measurement, thus placing the sample in darkness (Fig. 1). The sensor head could then be left in place for a predetermined interval, thereby dark-acclimating the sample. Fluorescence measurements made immediately prior to closing of the automated shutter provided background fluorescence values which could then be subtracted from sub-

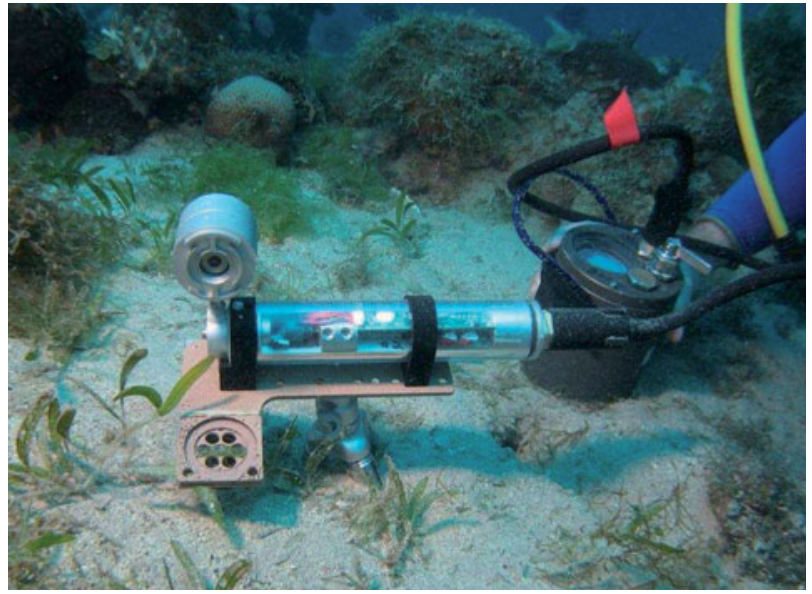

Fig. 1. Custom fluorometer holding a Halophila stipulacea leaf with automated shutter (left) and battery data/acquisition unit (right)

sequent values obtained from the seagrass samples when the sensor head was in a closed position. The other fluorometer design simply positioned the sensing part of the fluorometer close to the sample which was held in a clear acrylic sample holder; samples were exposed to ambient irradiance throughout the course of measurements. Each fluorometer was connected by cable to an independent submersible data-logger and power supply; previous experiments (authors' unpubl. data) demonstrated that the system can operate for at least $2 \mathrm{~d}$ on a single charge. Several fluorometers of both designs were deployed at each site and a single seagrass blade was held in the sample holder of the fluorometer with an upwards orientation; the irradiance sensor incorporated into each fluorometer likewise faced upwards. Care was taken during the deployments to minimise any disturbance of the seagrasses. The fluorometers were left in position for at least $24 \mathrm{~h}$. While the second design of fluorometer was programmed simply to measure $\Delta F / F_{\mathrm{m}}$ ' every $15 \mathrm{~min}$, the dark-acclimating shutter fluorometers were additionally programmed to remain closed for a $15 \mathrm{~min}$ interval once every $2 \mathrm{~h}$, thereby also allowing 12 measurements of $F_{\mathrm{v}} / F_{\mathrm{m}}$ during a $24 \mathrm{~h}$ interval. Examination of the $\phi_{\text {II }}$ data directly after the $F_{\mathrm{v}} / F_{\mathrm{m}}$ measurements suggested no apparent effect of the 15 min dark treatment on subsequent $\phi_{\text {II }}$ measurements, which would have manifested as an increase in $\phi_{\text {II }}$ values directly after each $F_{\mathrm{v}} / F_{\mathrm{m}}$ measurement.

Diel photosynthesis-irradiance curves. ETRs were calculated according to Genty et al. (1989) as the product of ambient irradiance, $\phi_{\mathrm{II}}, \mathrm{AF}$ at the time of measurement and 0.5 to account for electron sharing between photosystem I (PSI) and PSII. Diel photosynthesis-irradiance $(P-I)$ curves (Longstaff et al. 2002), (where ' $I$ ' represents non-wavelength-specific irradi- 
ance) were plotted using absorbed irradiance $\left(I_{\mathrm{a}}\right.$, Saroussi \& Beer 2007) for the abscissa; $I_{\mathrm{a}}$ was calculated as the product of incident irradiance $\left(I_{\mathrm{i}}\right), \mathrm{AF}$ and 0.5 , which describes the proportion of exciton energy shared between PSI and PSII. $P$ - $I$ curves were generated using data acquired over $24 \mathrm{~h}$ intervals. The exponential model of Webb et al. (1974) was used to derive values for $\mathrm{ETR}_{\max }$ and the photon to electron conversion efficiency $(\alpha)$ using non-linear least squares minimisation techniques and Sigmaplot software (Jandel Scientific). The saturation irradiance, $I_{\mathrm{k}}$, was calculated from $\mathrm{ETR}_{\max }$ and $\alpha$ by extrapolating a linear $P-I$ curve with slope $\alpha$ to $\mathrm{ETR}_{\max }$, and errors associated with $I_{\mathrm{k}}$ were determined by propagation from ETR $\mathrm{Eax}_{\text {max }}$ and $\alpha$. Non-saturating curves generated from the deeper plants were analysed using the Webb model, with initial parameter seed values obtained from the saturating curves of shallow plants. Thus values of ETR max $_{\text {m }}$ were extrapolated from the non-saturating data obtained in the field.

As the above curves were calculated using data pooled from both the morning and afternoon, estimates of $\mathrm{ETR}_{\max }$ necessarily could not reflect the observed maximum ETR at noon. Therefore, observed $\mathrm{ETR}_{\max }$ and $I_{\mathrm{k}}$ calculated using observed ETR $\mathrm{Emax}_{\text {were }}$ also presented. Values of $\alpha$ were assumed to be similar for both calculated and observed curves.

Fluorescence parameters and quenching analysis. Fluorescence parameters follow the notation of Van Kooten \& Snel (1990). $F$ or $F_{\mathrm{t}}$ denote steady state fluorescence under ambient irradiance. $F_{\mathrm{m}}{ }^{\prime}$ and $F_{\mathrm{m}}$ are maximal fluorescence obtained during a $0.8 \mathrm{~s}$ period of saturating light for samples exposed to ambient light or darkness, respectively. $F_{0}$ and $F_{o}^{\prime}$ represent minimal fluorescence of (respectively) dark-acclimated samples, or light-acclimated samples measured after a brief dark exposure after the shutter had closed. Kramer et al. (2004) described the analytical techniques that enabled the examination of the allocation of excitation energy to photochemistry $\left(\phi_{\mathrm{II}}\right)$ and 2 competing nonphotochemical pathways (downregulation, $\phi_{\mathrm{NPQ}}$ ) and other energy losses (basal intrinsic nonradiative decay in the present study, $\phi_{\mathrm{NO}}$ ).

$$
\begin{aligned}
& \mathrm{NPQ}=\left(F_{\mathrm{m}}-F_{\mathrm{m}}{ }^{\prime}\right) / F_{\mathrm{m}}{ }^{\prime} \\
& \mathrm{qP}=\left(F_{\mathrm{m}}{ }^{\prime}-F_{\mathrm{t}}\right) /\left(F_{\mathrm{m}}{ }^{\prime}-F_{\mathrm{o}}{ }^{\prime}\right) \\
& \phi_{\mathrm{NO}}=1 /\left\{\mathrm{NPQ}+1+\mathrm{qP}\left[\left(F_{\mathrm{m}} / F_{\mathrm{o}}\right)-1\right]\right\} \\
& 1=\phi_{\mathrm{NO}}+\phi_{\mathrm{NPQ}}+\phi_{\mathrm{II}} \\
& \mathrm{qCu}=\left(F_{\mathrm{m}}{ }^{\prime}-F_{\mathrm{t}}\right) /\left[\left(F_{\mathrm{t}}-F_{\mathrm{o}}{ }^{\prime}\right)+F_{\mathrm{m}}{ }^{\prime}-F_{\mathrm{o}}{ }^{\prime}\right]
\end{aligned}
$$

where qP represents photochemical quenching, and qcu represents the proportion of open reaction centres (Kramer et al. 2004), assuming a value of 0.5 as the exciton transfer probability parameter, and assuming an intermediate model for reaction centre connectivity (Lavergne \& Trissl 1995).

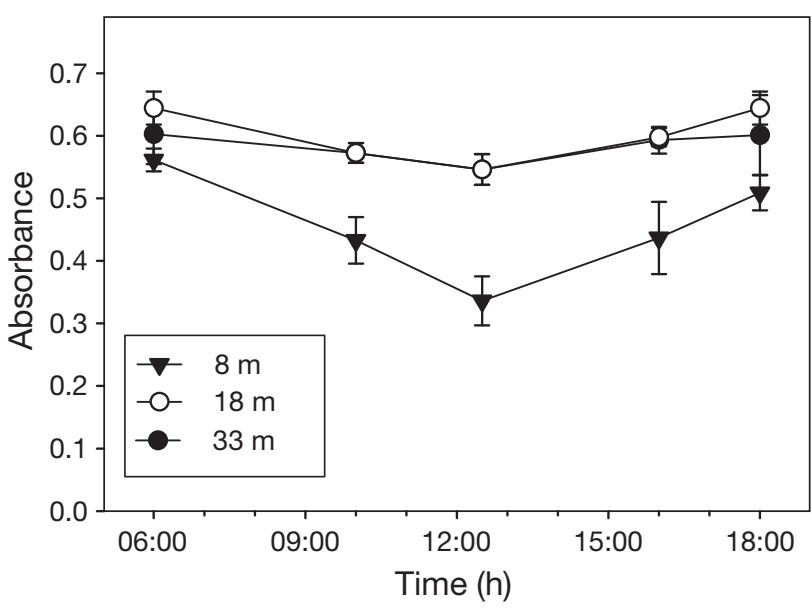

Fig. 2. Halophila stipulacea. Relative absorbance of leaves at 8,18 and $33 \mathrm{~m}$ depth measured from dawn to dusk. Values are mean \pm SD of 12 replicate measurements

\section{RESULTS}

\section{Absorbance}

AF values of Halophila stipulacea at $8 \mathrm{~m}$ declined significantly from $\sim 0.60$ to a midday minimum of 0.34 , rising again in the afternoon to values similar to, but slightly lower than, predawn values (Fig. 2). We ascribe this difference in AF to the chloroplast clumping phenomenon as described by Sharon \& Beer (2008). In contrast, AF values of the deeper growing plants only declined slightly during the day, with marginally greater predawn and dusk values compared to the $8 \mathrm{~m}$ plants.

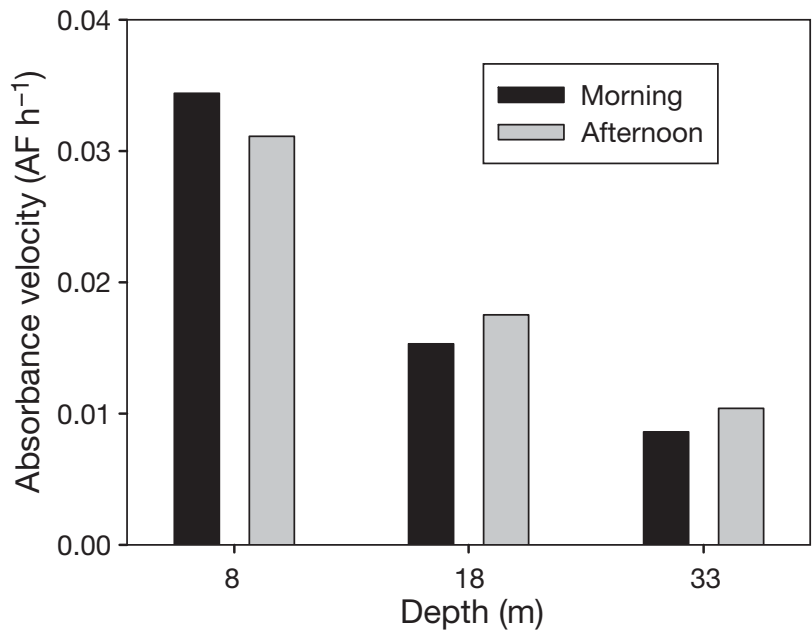

Fig. 3. Halophila stipulacea. Rate of change of absorption factor (AF) at 8, 18 and $33 \mathrm{~m}$ before and after midday. Values presented are absolute; morning values are negative and afternoon values are positive 
At each depth, the absolute value of the rate of decline in AF during the morning was similar to that during the afternoon (Fig. 3). The magnitude was greatest for shallow seagrasses and least for the deepest seagrasses, indicative of a more marked response in shallow water. Data describing AF acquired at dawn satisfied the assumptions of homogeneity, and AF at $8 \mathrm{~m}(0.558 \pm 0.03$; all reported values are mean \pm SD) was significantly less than values at the deeper sites which did not differ significantly (33 m: $0.604 \pm 0.05 ; 18 \mathrm{~m}: 0.632 \pm 0.03 ; F=14.2$, $\mathrm{p}>0.001)$. AF measured at dusk was significantly different at the 3 sites $(8 \mathrm{~m}: 0.509 \pm 0.03 ; 18 \mathrm{~m}: 0.642 \pm 0.04$; $33 \mathrm{~m}: 0.598 \pm 0.06 ; F=26.6, \mathrm{p}>0.000)$.

\section{Morning and afternoon fluctuation in $\phi_{\mathrm{II}}, F_{\mathrm{v}} / F_{\mathrm{m}}$ and ETR}

Minimum midday values of $\phi_{\text {II }}$ at 8,18 and $33 \mathrm{~m}$ dropped to less than $0.1,0.2$ and 0.3 , respectively,

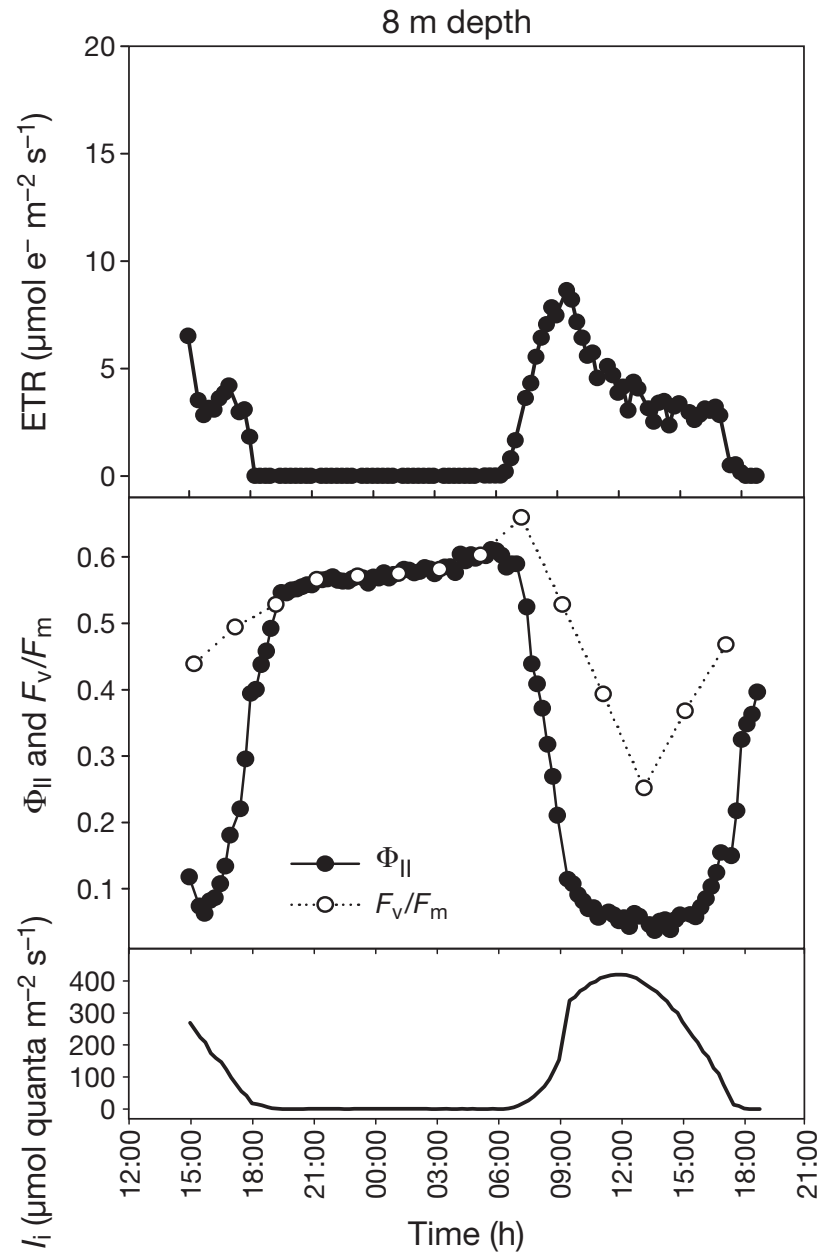

Fig. 4. Halophila stipulacea. Diel variation in electron transport rate (ETR), quantum yield of PSII $\left(\phi_{\text {II }}\right)$ and incident irradiance $\left(I_{\mathrm{i}}\right)$ of a single representative leaf at $8 \mathrm{~m}$ depth reflecting the decline in midday irradiance with depth (Figs. 4-6). After sunset, $\phi_{\text {II }}$ of plants at all depths increased rapidly to values around 0.6 , followed by a slow gradual increase throughout the night. $F_{\mathrm{v}} / F_{\mathrm{m}}$ as measured after in situ dark-acclimation for $15 \mathrm{~min}$, declined during the day with declining $\phi_{\text {II }}$ and recovered rapidly at dusk assuming the same values as $\phi_{\text {II }}$ during the night. $F_{\mathrm{v}} / F_{\mathrm{m}}$ continued to rise slightly after dawn while $\phi_{\text {II }}$ commenced its decline

ETRs tended to increase rapidly during the morning and decline more slowly in the afternoon. This can be seen more clearly in Fig. 7 where morning values of ETRs for shallow plants are far greater than afternoon values for the same absorbed irradiance. The reduced differences between morning and afternoon ETRs of deeper plants is largely a consequence of the reduced irradiance, as can be seen when comparing ETRs where $I_{\mathrm{a}}$ is $\sim 20$ to $160 \mu \mathrm{mol}$ photons $\mathrm{m}^{-2} \mathrm{~s}^{-1}$ for experiments conducted at the 3 depths (Fig. 7). Clearly, ETR $_{\text {max }}$ calculated from pooled morning and afternoon

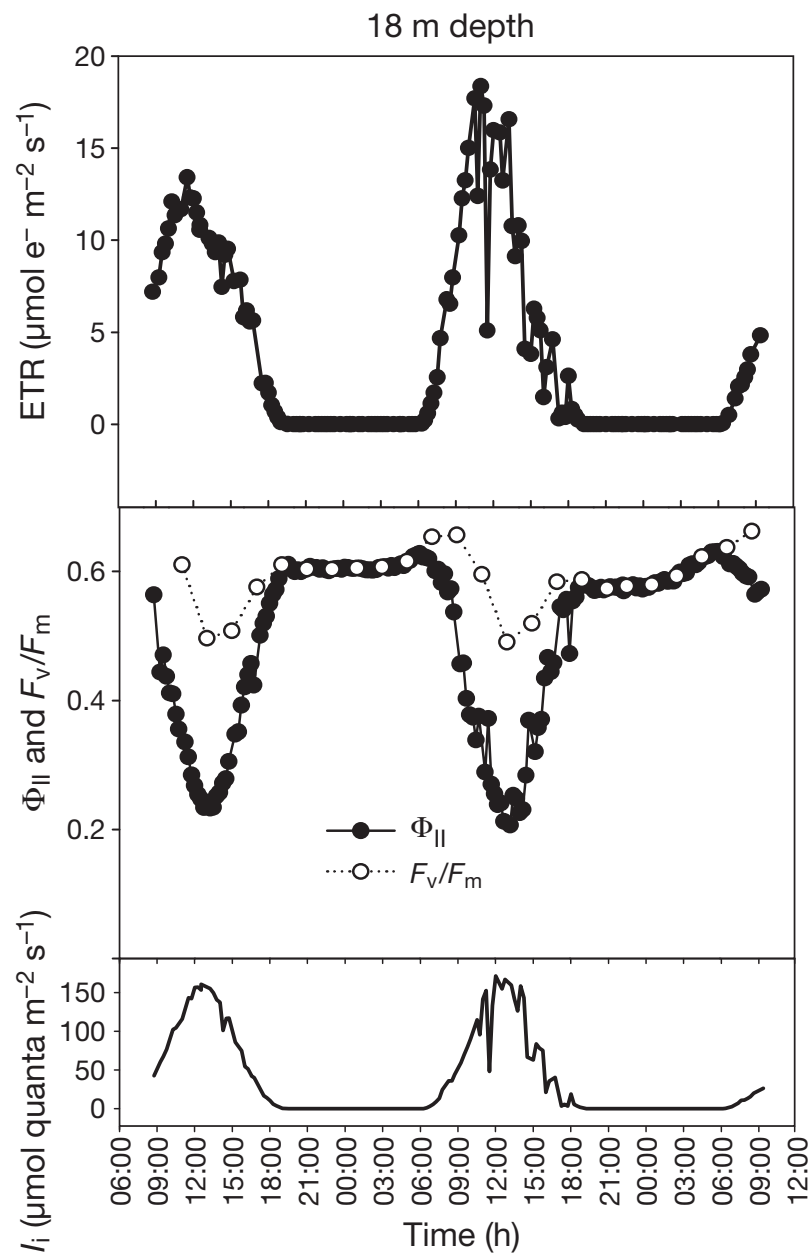

Fig. 5. Halophila stipulacea. Diel variation in electron transport rate (ETR), quantum yield of PSII $\left(\phi_{\text {II }}\right)$ and incident irradiance $\left(I_{\mathrm{i}}\right)$ of a single representative leaf at $18 \mathrm{~m}$ depth 


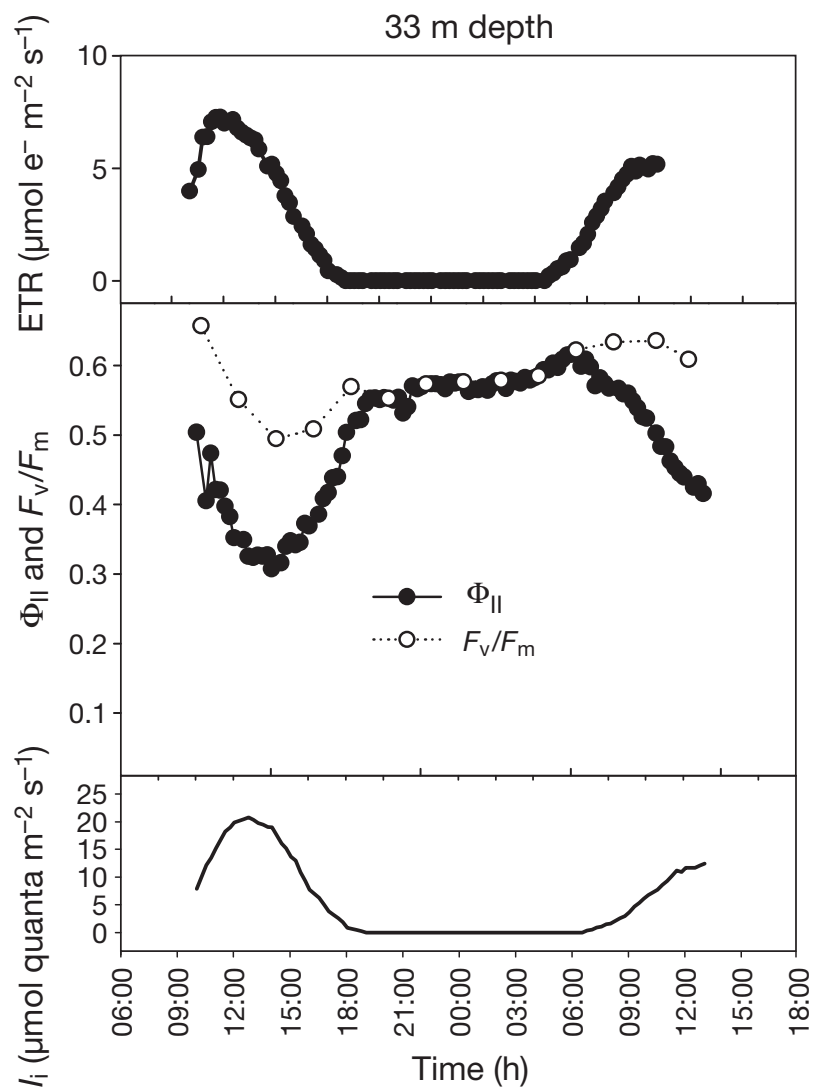

Fig. 6. Halophila stipulacea. Diel variation in electron transport rate (ETR), quantum yield of PSII $\left(\phi_{\text {II }}\right)$ and incident irradiance $\left(I_{\mathrm{i}}\right)$ of a single representative leaf at $33 \mathrm{~m}$ depth

Table 1. Halophila stipulacea. Observed maximum electron transport rate $\left(\mathrm{ETR}_{\max }, \mu \mathrm{mol}\right.$ electrons $\left.\mathrm{m}^{-2} \mathrm{~s}^{-1}\right)$ and calculated photosynthetic parameters $\mathrm{ETR}_{\max }$ initial slope of the $P-I$ curve $\left(\alpha\right.$; electrons photon $\left.{ }^{-1}\right)$, saturation irradiance $I_{\mathrm{k}}$ (derived from calculated and observed ETR $\max$ values) and incident irradiance $I_{\mathrm{i}}$ ( $\mu \mathrm{mol}$ photons $\mathrm{m}^{-2} \mathrm{~s}^{-1}$ ) measured in situ at 8,18 and $33 \mathrm{~m}$. ETRs were derived from multiple modulated chlorophyll fluorescence measurements and estimates of absorbed irradiance $\left(I_{\mathrm{a}}\right)$ obtained over intervals $\geq 24 \mathrm{~h}$. Each value represents parameter estimates $( \pm \mathrm{SD})$ derived from a single experiment conducted over a $24 \mathrm{~h}$ interval on an individual leaf. calc.: calculated; obs.: observed

\begin{tabular}{|c|c|c|c|c|c|c|}
\hline $\begin{array}{l}\text { Depth } \\
\text { (m) }\end{array}$ & $\begin{array}{l}\text { ETR } \\
\text { (calc.) }\end{array}$ & $\begin{array}{l}\max \\
\text { (obs.) }\end{array}$ & $\alpha$ & (calc.) $^{I_{\mathrm{k}}}$ & (obs.) & $\begin{array}{c}I_{\mathrm{i}} \\
(\max )\end{array}$ \\
\hline 8 & $\begin{array}{l}7.04 \pm 0.4 \\
7.44 \pm 0.6 \\
5.28 \pm 0.2\end{array}$ & $\begin{array}{c}18.67 \\
21.24 \\
8.60\end{array}$ & $\begin{array}{l}0.80 \pm 0.4 \\
0.77 \pm 0.4 \\
0.70 \pm 0.2\end{array}$ & $\begin{array}{l}8.75 \pm 4.1 \\
9.65 \pm 5.4 \\
7.56 \pm 1.9\end{array}$ & $\begin{array}{l}23.3 \\
27.6 \\
12.3\end{array}$ & $\begin{array}{l}419 \\
419 \\
419\end{array}$ \\
\hline 18 & $\begin{array}{c}17.05 \pm 2.0 \\
4.90 \pm 0.4\end{array}$ & $\begin{array}{c}18.35 \\
8.84\end{array}$ & $\begin{array}{l}0.55 \pm 0.1 \\
0.41 \pm 0.1\end{array}$ & $\begin{array}{l}30.84 \pm 4.7 \\
12.02 \pm 2.3\end{array}$ & $\begin{array}{l}33.4 \\
21.6\end{array}$ & $\begin{array}{l}167 \\
167\end{array}$ \\
\hline 33 & $\begin{array}{c}9.87 \pm 0.6 \\
20.69 \pm 2.8\end{array}$ & $\begin{array}{l}7.24 \\
9.22\end{array}$ & $\begin{array}{l}0.57 \pm 0.0 \\
0.58 \pm 0.0\end{array}$ & $\begin{array}{l}17.25 \pm 1.3 \\
35.87 \pm 4.9\end{array}$ & $\begin{array}{l}12.7 \\
15.9\end{array}$ & $\begin{array}{l}75 \\
75\end{array}$ \\
\hline
\end{tabular}
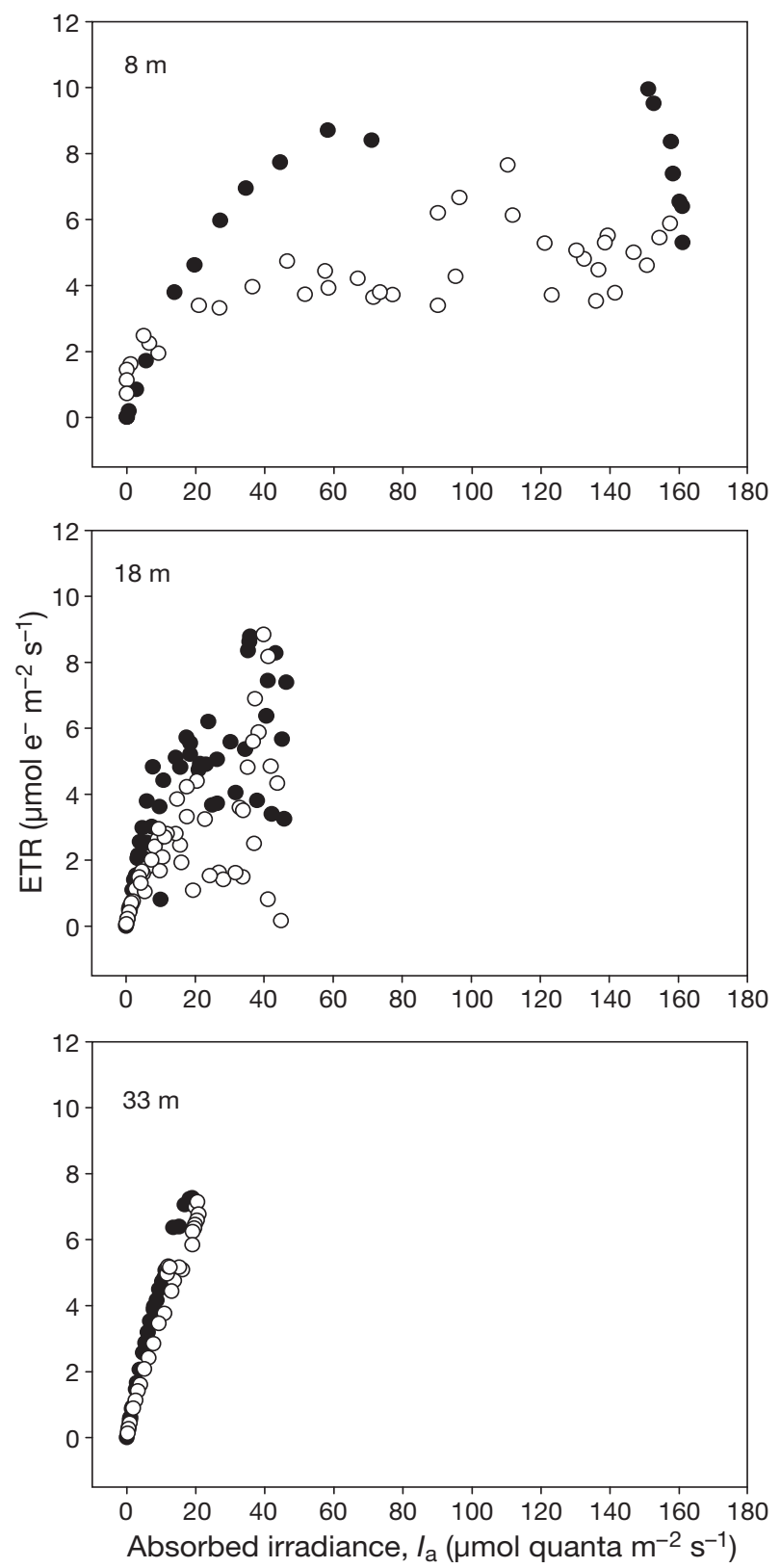

Fig. 7. Halophila stipulacea. Representative photosynthesisirradiance curves measured over $\geq 24 \mathrm{~h}$ at 8,18 and $33 \mathrm{~m}$ depth (see also Table 1). Absorbed irradiance $\left(I_{\mathrm{i}} \times \mathrm{AF} \times 0.5\right)$ was used to calculate electron transport rate and was used for the abscissa. Closed and open circles represent morning and afternoon measurements, respectively

data underestimated observed ETR max $_{\text {when noonday }}$ irradiance was high (Table 1, Fig. 7), while calculated values for the deeper plants more closely approximated observed values. Observed values of ETR $_{\max }$ ranged from 7 to $21 \mu \mathrm{mol}$ electrons $\mathrm{m}^{-2} \mathrm{~s}^{-1}$, with lower values observed at all depths and higher values only observed at shallow and intermediate depths (Table 1). 


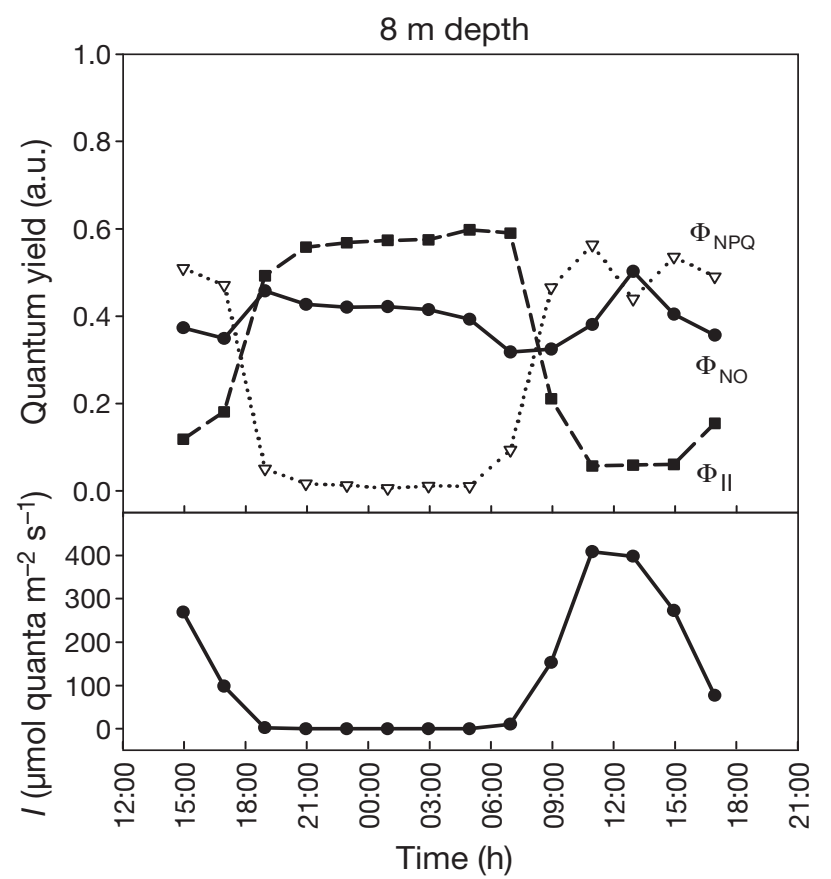

Fig. 8. Halophila stipulacea. Diel variation in quantum yields (atomic units, a.u.) of PSII fluorescence $\left(\phi_{\text {III }}\right)$, non-photochemical quenching by down-regulation $\left(\phi_{\mathrm{NPQ}}\right)$ and other non-photochemical quenching $\left(\phi_{\mathrm{NO}}\right)$ of a single representative leaf at $8 \mathrm{~m}$ depth. Incident irradiance at the depth of the experiment is presented in $\mu \mathrm{mol}$ quanta $\mathrm{m}^{-2} \mathrm{~s}^{-1}$

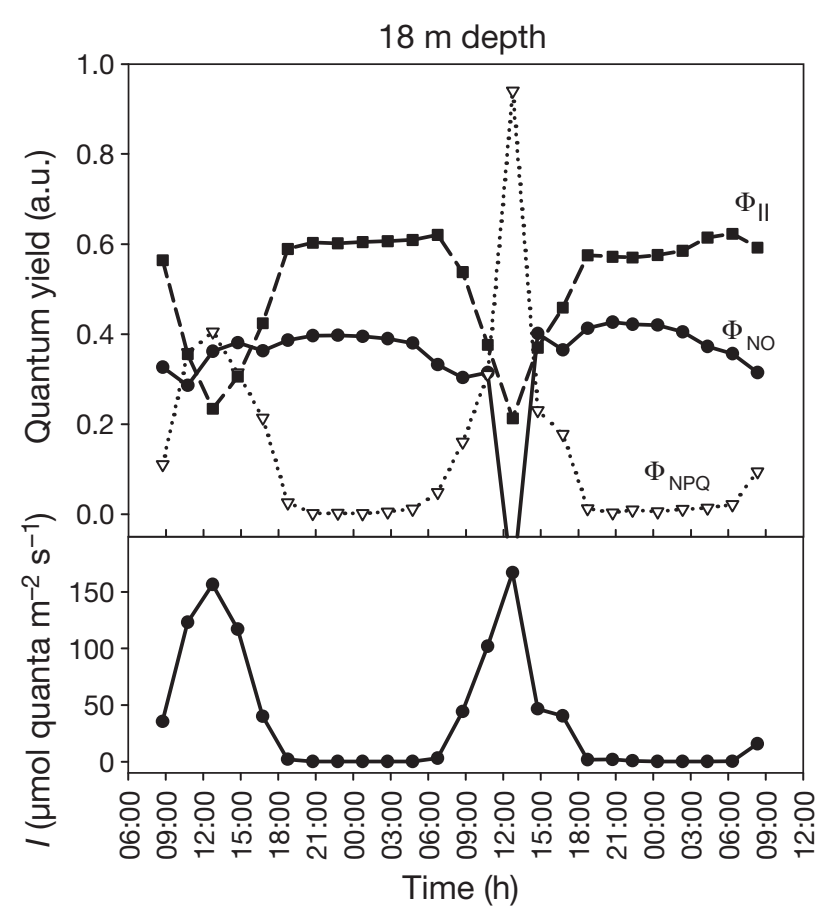

Fig. 9. Halophila stipulacea. Diel variation in quantum yields (atomic units, a.u.) of PSII fluorescence $\left(\phi_{\mathrm{II}}\right)$, non-photochemical quenching by down-regulation $\left(\phi_{\mathrm{NPQ}}\right)$ and other non-photochemical quenching $\left(\phi_{\mathrm{NO}}\right)$ of a single representative leaf at $18 \mathrm{~m}$ depth. Incident irradiance at the depth of the experiment is presented in $\mu \mathrm{mol}$ quanta $\mathrm{m}^{-2} \mathrm{~s}^{-1}$

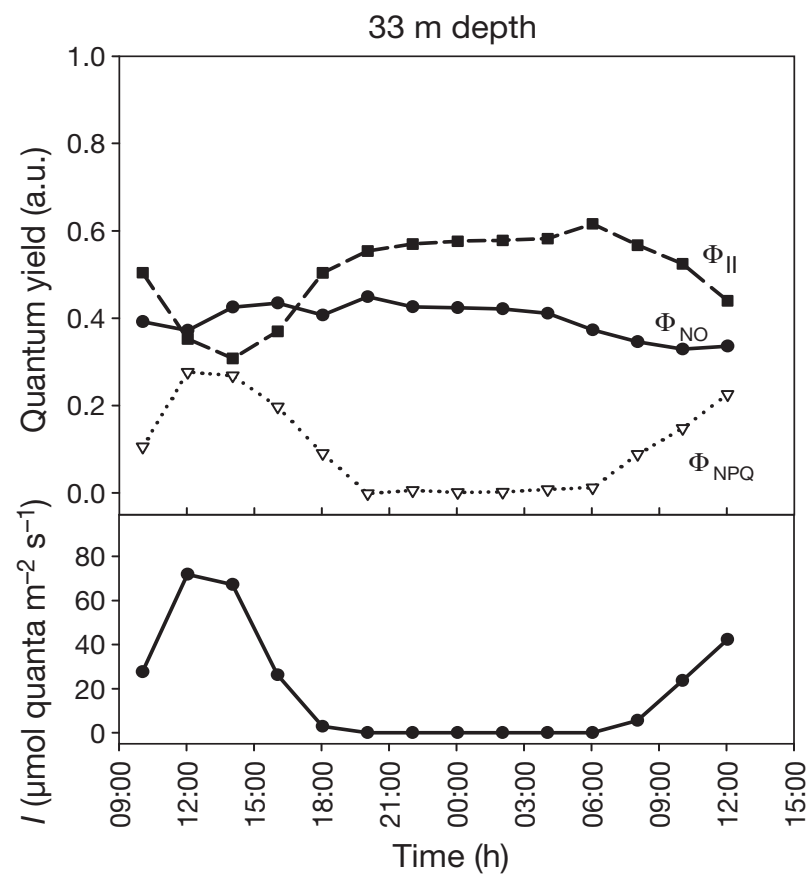

Fig. 10. Halophila stipulacea. Diel variation in quantum yields (atomic units, a.u.) of PSII fluorescence $\left(\phi_{\text {III }}\right)$, non-photochemical quenching by down-regulation $\left(\phi_{\mathrm{NPQ}}\right)$ and other nonphotochemical quenching $\left(\phi_{\mathrm{NO}}\right)$ of a single representative leaf at $33 \mathrm{~m}$ depth. Incident irradiance at the depth of the experiment is presented in $\mu \mathrm{mol}$ quanta $\mathrm{m}^{-2} \mathrm{~s}^{-1}$

The daily mean initial slope of the $P$ - $I$ curves, $\alpha$, ranged from 0.41 to 0.80 , with greater values at the shallow site. While calculated values of saturation irradiance $\left(I_{\mathrm{k}}\right)$ were higher for deeper plants, values derived from observed ETR $\mathrm{Eax}_{\max }$ values showed no obvious differences between depths and ranged between 12 and $33 \mu \mathrm{mol}$ photons $\mathrm{m}^{-2} \mathrm{~s}^{-1}$.

\section{Non-photochemical quantum yields}

At $8 \mathrm{~m}$ depth, $\phi_{\mathrm{NPQ}}$ declined from midday values of around 0.6 to near zero at night (Fig. 8). At $18 \mathrm{~m}$ depth, $\phi_{\mathrm{NPQ}}$ similarly dropped to near zero at night, but was generally around 0.4 at midday, except for an (presumably erroneous) anomaly where $\phi_{\mathrm{NPQ}}$ reached its maximal value of 1 at midday (Fig. 9) and $\phi_{\text {NO }}$ was underestimated at $<0$. At $33 \mathrm{~m}$ depth, $\phi_{\mathrm{NPQ}}$ only rose to about 0.3 at midday, also dropping to zero at night. $\phi_{\text {NO }}$ was steady at about 0.4 in plants at all depths during the night. At $8 \mathrm{~m}$ depth, this value declined with light onset, and then increased at midday to about 0.5 (Fig. 8). A similar pattern could be seen at $18 \mathrm{~m}$ where a strong midday decline was evident (Fig. 9). The decline was also apparent, but far less marked, for plants at $33 \mathrm{~m}$ depth (Fig. 10). The range of $\phi_{\mathrm{NO}}$ values declined with reduced irradiance from about $20 \%$ for the shallow plants to about $10 \%$ for the deep plants. 


\section{DISCUSSION}

The rate of decline in absorbance of Halophila stipulacea was greatest in shallow waters, supporting previous observations that high light exposure causes a physiological response in this species (Sharon \& Beer 2008). This response was less marked for the deeper plants, with progressively decreasing rates of change over the day with increasing depth. These data suggest that, with increasing depth, there is a diminishing requirement for chloroplast translocation throughout the day. Consequently, resources used for chloroplast movement in shallow plants can be reallocated to other processes. This capacity to acclimate during the day to elevated irradiance appears to be inducible, as shown by Sharon et al. (2009), where translocated seagrasses assumed similar responses to those resident at each depth.

$P-I$ curves are commonly used in aquatic photosynthesis research to characterise the response of metabolic rates to changing irradiance, and ETRs are often presented because chlorophyll fluorescence (from which ETR is derived) can be easily measured. However, recent research has demonstrated the importance of diel changes in parameters often assumed to be invariant (Belshe et al. 2007). For example, diel changes in absorbance of Halophila stipulacea due to chloroplast clumping clearly influenced calculated ETRs (Sharon \& Beer 2008), and Saroussi \& Beer (2007) argued that $I_{\mathrm{a}}$ rather than $I_{\mathrm{i}}$ should be used in $P$-I curves when calculating $\alpha$ and $I_{\mathrm{k}}$. Both studies demonstrated that apparent differences in ETR due to seasonal or depth effects may be non-significant when the $P$ - $I$ curve is constructed using $I_{\mathrm{a}}$ rather than $I_{\mathrm{i}}$. The results of the present study show wide variation in maximum ETRs of $P-I$ curves measured across the depth range (Table 1). The differences in values of ETR $_{\max }$ and $\alpha$ derived from curves using pooled data versus observed values of $\mathrm{ETR}_{\max }$ demonstrate the additional complexity of analysing diel $P$ - $I$ curves when representative parameter values are desired, and the use of observed data may be generally advised if representative parameters are required.

The wide variation in parameter estimates across the depth gradient in the present study may in part be due to variability in leaf condition and orientation, as leaves were fixed in a horizontal position to enable measurement. As the propagated errors associated with $I_{\mathrm{k}}$ values were considerably greater than those associated with ETR $\max _{\text {ax }}$ and $\alpha, I_{\mathrm{k}}$ should be treated with caution when used to compare treatments.

At $8 \mathrm{~m}$ depth, $\phi_{\text {II }}$ declined below 0.1 (Fig. 4). When $\phi_{\text {II }}$ reaches this critical value (due to increasing irradiance), electron transport estimates become less suitable as descriptors of photosynthetic rates (Beer \&
Axelsson 2004) as more electrons are diverted from photochemistry. Thus, Halophila stipulacea at $8 \mathrm{~m}$ has more than enough light to conduct photosynthesis during the day, and accordingly diverts the excess energy absorbed into NPQ (Fig. 8). Also, the fact that ETRs were lower in the afternoon than before noon at comparable irradiances points towards a dynamic photoinhibition taking place after several hours of high irradiance. A similar phenomenon of hysteretic diurnal ETRs was also described for shallow-growing corals in the Gulf of Aqaba (Winters et al. 2003) and the seagrass Thalassia testudium (Belshe et al. 2007, 2008). At the 18 and $33 \mathrm{~m}$ sites, $\phi_{\text {II }}$ does not exceed this threshold value (Figs. $5 \& 6$ ) and accordingly diverts less excess energy into NPQ. Even at $33 \mathrm{~m}$ there is substantial $N P Q$, with $30 \%$ of exciton energy diverted to this sink at noon (Fig. 10). However, this may not be surprising as $H$. stipulacea has been observed at depths far in excess of $33 \mathrm{~m}$ (Lipkin 1979).

The automated dark-acclimation function enables the measurement of dark-acclimated fluorescence in the field without user intervention, as well as the application of a far-red light. Until now this not been possible and, as pointed out by Maxwell \& Johnson (2000) and others, this enables the significant limitations of dark-acclimating samples in the field to be overcome. Using this technique, our field measurements enable us to determine the extent that long-term NPQ (qI, or photoinhibitory quenching; Müller et al. 2001) contributes to the decline in photon conversion efficiency relative to the other more rapidly relaxing NPQ components qE (energy-dependent quenching) and qT (state-transition quenching). As expected, all 3 forms of NPQ are active during the day, hence the difference between effective and maximal quantum yield values. However, at night, short-term relaxation of qE and qT has occurred and the remaining NPQ (qI) is evident for both effective and maximal quantum yields. Here, qI can be seen as the difference between the predawn maximum quantum yield and nighttime quantum yield.

In addition to this ability to quantify these 3 different phases of NPQ according to relaxation kinetics, in situ dark-acclimation also enables a detailed deconvolution of in situ-derived NPQ components over a diel cycle and enables the direct estimation of NPQparameters described in the literature (Kramer et al. 2004, Kornyeyev \& Holaday 2008). Here, the relatively straightforward deconvolution described by Kramer et al. (2004) is employed, where the term for basal intrinsic non-radiative decay, $\phi_{\mathrm{NO}}$, includes both constitutive thermal dissipation and thermal dissipation associated with PSII photo-inactivation (Kornyeyev \& Holaday 2008).

$\phi_{\mathrm{NO}}$ remained fairly constant at between 30 and $40 \%$ at all 3 depths, with slightly more variation in shallow 
waters and slightly lower values in deep waters. Thus, Halophila stipulacea dissipates a large proportion of light energy through intrinsic decay apparently regardless of depth within the depth range examined. The water clarity in the Gulf of Aqaba is such that photosynthetic organisms at $33 \mathrm{~m}$ are unlikely to be light limited (Winters et al. 2003). As $\phi_{\text {NO }}$ describes the dissipation of excess energy and is relatively constant throughout the diel period in the deepwater plants, it partly represents a constitutive property of $H$. stipulacea rather than a high-light-induced acclimatory mechanism. The reduced capacity for photosynthetic photon conversion during the day in deep water leaves occurs at a depth where one might consider irradiance to be limiting; clearly it is not and the daytime decline in $\phi_{\text {II }}$ of deepwater plants is apparently an acceptable trade-off for the capacity to rapidly divert excess light energy. If one were to extrapolate the daily maximum $\phi_{\text {NO }}$ of $H$. stipulacea measured over a diel period to $H$. stipulacea at deeper depths, the less-constitutive portion may become negligible at the depth limit of this species; such an approach might be used to suggest a species' depth limit. The present study invites the question of the cost of maintaining a constitutive capacity to dissipate excitons versus the cost of maintaining a down-regulatory capacity for dissipation.

Acknowledgements. This work was conducted in conjunction with the Bat Sheva de Rothchild seminar on Gross and Net Primary Productivity within the framework of the 8th International workshop of Group for Aquatic Primary Productivity (GAP). The authors thank the Inter-University Institute for Marine Sciences of Eilat for logistic support, in particular I. Berman-Frank, and O. Ben Shaprut and D. Tobias for diving support.

\section{LITERATURE CITED}

Beer S, Axelsson L (2004) Limitations in the use of PAM fluorometry for measuring photosynthetic rates of macroalgae at high irradiances. Eur J Phycol 39:1-7

Beer S, Waisel Y (1982) Effects of light and pressure on photosynthesis in two seagrasses. Aquat Bot 13:331-337

Beer S, Vilenkin B, Weil A, Veste M, Susel L, Eshel A (1998) Measuring photosynthetic rates in seagrasses by pulse amplitude modulated (PAM) fluorometry. Mar Ecol Prog Ser 174:293-300

Beer S, Larsson C, Poryan O, Axelsson L (2000) Photosynthetic rates of Ulva (Chlorophyta) measured by pulse amplitude modulated (PAM) fluorometry. Eur J Phycol 35: 69-74

Belshe EF, Durako MJ, Blum JE (2007) Photosynthetic rapid light curves (RLC) of Thalassia testudinum exhibit diurnal variation. J Exp Mar Biol Ecol 342:253-268

Belshe EF, Durako MJ, Blum JE (2008) Diurnal light curves and landscape-scale variation in photosynthetic characteristics of Thalassia testudinum in Florida Bay. Aquat Bot 89:16-22

Edwards AJ, Head SM (eds) (1987) Key environments: Red Sea. Pergamon Press, Oxford
Genty B, Briantias JM, Baker NR (1989) The relationship between the quantum yield of photosynthetic electron transport and quenching of chlorophyll fluorescence. Biochim Biophys Acta 990:87-92

Hulings NC (1979) The ecology, biometry and biomass of the seagrass Halophila stipulacea along the Jordanian coast of the Gulf of Aqaba. Bot Mar 22:425-430

Kornyeyev D, Holaday AS (2008) Corrections to current approaches used to calculate energy partitioning in photosystem 2. Photosynthetica 46:170-178

> Kramer DM, Johnson G, Kiirats O, Edwards GE (2004) New fluorescence parameters for the determination of $Q_{A}$ redox state and excitation energy fluxes. Photosynth Res 79: 209-218

> Larkum AWD (1976) Ecology of Botany Bay. I. Growth of Posidonia australis (Brown) Hook. f. in Botany Bay and other bays of the Sydney basin. Aust J Mar Freshw Res 27: $117-127$

> Lavergne J, Trissl HW (1995) Theory of fluorescence induction in photosystem II: derivation of analytical expressions in a model including exciton-radical-pair equilibrium and restricted energy transfer between photosynthetic units. Biophys J 68:2474-2492

> Lee KS, Park SR, Kim YK (2007) Effects of irradiance, temperature, and nutrients on growth dynamics of seagrasses: a review. J Exp Mar Biol Ecol 350:144-175

Lipkin Y (1979) Quantitative aspects of seagrass communities particularly those dominated by Halophila stipulacea, in Sinai (northern Red Sea). Aquat Bot 7:119-128

Longstaff BJ, Kildea T, Runcie JW, Cheshire A and others (2002) An in situ study of photosynthetic oxygen exchange and electron transport rate in the marine macroalga Ulva lactuca (Chlorophyta). Photosynth Res 74:281-293

> Maxwell K, Johnson GN (2000) Chlorophyll fluorescencea practical guide. J Exp Bot 51:659-668

McCree KJ (1981) Photosynthetically active radiation. In: Lang OL, Novel P, Osmond B, Ziegler H (eds) Physiological plant ecology. Encyclopedia of Plant Physiology, Vol 12A. Springer-Verlag, Berlin

Müller P, Li XP, Niyogi KK (2001) Non-photochemical quenching: a response to excess light energy. Plant Physiol 125: 1558-1566

Orth RJ, Carruthers TJB, Dennison WC, Duarte CM and others (2006) A global crisis for seagrass ecosystems. Bioscience 56:987-996

Ralph PJ, Durako MJ, Enríquez S, Collier CJ, Doblin MA (2007) Impact of light limitation on seagrasses. J Exp Mar Biol Ecol 350:176-193

Runcie JW, Durako MJ (2004) Among-shoot variability and leaf-specific absorptance characteristics affect diel estimates of in situ electron transport of Posidonia australis. Aquat Bot 80:209-220

Runcie JW, Riddle MJ (2004) Measuring variability in chlorophyll-fluorescence-derived photosynthetic parameters in situ with a programmable multi-channel fluorometer. Funct Plant Biol 31:559-562

Runcie JW, Riddle MJ (2006) Photosynthesis of marine macroalgae in ice-covered and ice-free environments in East Antarctica. Eur J Phycol 41:223-233

Saroussi S, Beer S (2007) Alpha and quantum yield of aquatic plants derived from PAM fluorometry: uses and misuses. Aquat Bot 86:89-92

Schwarz AM, Hellblom F (2002) The photosynthetic light response of Halophila stipulacea growing along a depth gradient in the Gulf of Aqaba, the Red Sea. Aquat Bot 74: 263-272

Schwarz AM, Hawes I, Andrew N, Norkko A, Cummings V, Thrush S (2003) Macroalgal photosynthesis near the 
southern global limit for growth; Cape Evans, Ross Sea, Antarctica. Polar Biol 26:789-799

Sharon Y, Beer S (2008) Diurnal movements of chloroplasts in Halophila stipulacea and their effect on PAM fluorometric measurements of photosynthetic rates. Aquat Bot 88: 273-276

Sharon Y, Silva J, Santos R, Runcie J (2009) Photosynthetic responses of Halophila stipulacea to a light gradient. II. Acclimations following transplantations. Aquat Biol 7:153-157

Submitted: November 28, 2008; Accepted: April 24, 2009
Van Kooten O, Snel JFH (1990) The use of chlorophyll fluorescence nomenclature in plant stress physiology. Photosynth Res 27:121-133

Webb WL, Newton M, Starr D (1974) Carbon dioxide exchange of Alnus rubra: a mathematical model. Oecologia 17:281-291

Winters G, Loya Y, Rottgers R, Beer S (2003) Photoinhibition in shallow-water colonies of the coral Stylophora pistillata as measured in situ. Limnol Oceanogr 48:1388-1393

Proofs received from author(s): June 9, 2009 